\title{
$\pi^{ \pm}-p$ AND $p-p$ ELASTIC SCATTERING AT 8.5, 12.4 AND $18.4 \mathrm{GeV} / \mathrm{c}$
}

\author{
CERN, Bologna, Liverpool, Machigan Collaboration, \\ CERN, Geneva and University of Bologna \\ (Presented by G. GIACOMELLI)
}

An experiment on elastic scattering, using the spark chamber technique, has been carried out at the CERN Proton Synchrotron. In this paper results are given for $\pi^{-}-p$ and $p-p$ elastic scattering at incident momenta of 8.5 , 12.4 and $18.4 \mathrm{GeV} / \mathrm{c}$, and for $\pi^{+}-p$ at 8.5
A scintillation counter system preselected the possible elastic scattering events. It consisted essentially of a triple coincidence of the incident, scattered, and recoil particles, in addition to a number of anticoincidences. The momenta of incident and scattered partic-

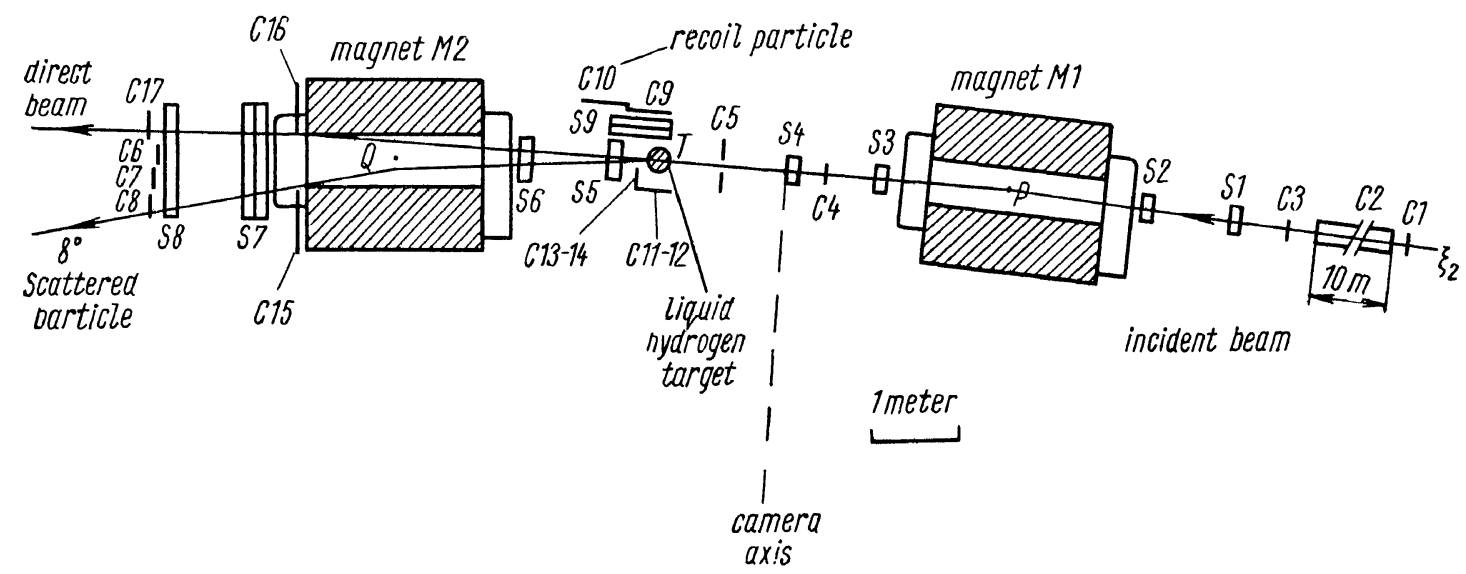

Fig. 1. Experimental lay-out. Spark chambers $S_{1}-S_{4}$ detect the incident particle, $S_{5}-S_{8}$ the scattered particle and $S_{9}$ the recoil proton. $C_{2}$ is a $10 \mathrm{~m}$ long threshold Cerenkov counter. The counters $C_{1}-C_{4}$ define the incident beam, $C_{5}-C_{6}$ detect the recoil proton and $C_{7}-C_{9}$ the scattered particle. $A_{1}-A_{8}$ are anticoincidence counters.

and $12.4 \mathrm{GeV} / \mathrm{c}$. Data were taken with and without the requirement of the proton recoil coincidence.

Our results confirm previously reported observations from other experiments on the nonshrinking of the $\pi^{ \pm}-p$ diffraction peaks and on the shrinking of the $p-p$ diffraction peak $[1-3]$. We find no significant difference in the behaviour of $\pi^{+}-p$ scattering compared with $\pi^{-}-p$ scattering.

The experimental layout is shown in Fig. 1. The beam, from an internal target, was counted by a system of counters among which a $10 \mathrm{~m}$ long hydrogen gas threshold Cerenkov counter, $C_{2}$ used in coincidence for $\pi-p$ scattering, in anticoincidence for $p-p$ scattering. The pion beams had a muon contamination of $(5-6) \%$. The beam was focused onto a cylindrical liquid hydrogen target of $20 \mathrm{~cm}$ diameter. les are determined by magnetic deflection to an accuracy of $\pm 1.5 \%$. The 18 views of the 9 chambers (one horizontal and one vertical view for each chamber) were brought together in a single picture by a system of 38 plane mirrors. The camera imaged an object plane at $17 \mathrm{~m}$ distance with a linear demagnification of 55 onto $35 \mathrm{~mm}$ film. Spherical field lenses were used over the larger spark chambers $S_{5}-S_{9}$ to reduce parallax.

350.000 useful pictures were taken.

About one third of these pictures were scanned on scanning projectors and events not obviously inelastic were measured by means of digitized tables either measuring points or lines.

The remaining pictures were scanned and measured entirely automatically with the Haugh-Powell Device (HPD) on-line with the 
CERN IBM 7090. computer. A flying light spot of $15 \mu$ scanned the film with a line spacing of $60 \mu$. The precision of a digitization is about $5 \mu$.

The speed of processing for this experiment was 1200 pictures per hour. The precision obtained by the HPD is almost a factor of 2 better than that achieved by digitized tables; for our experiment it amounts to $\pm 0.3 \mathrm{~mm}$ per point, $\pm 0.5 \mathrm{mrad}$ per direction, in real space. The selection criteria for elastic events are the

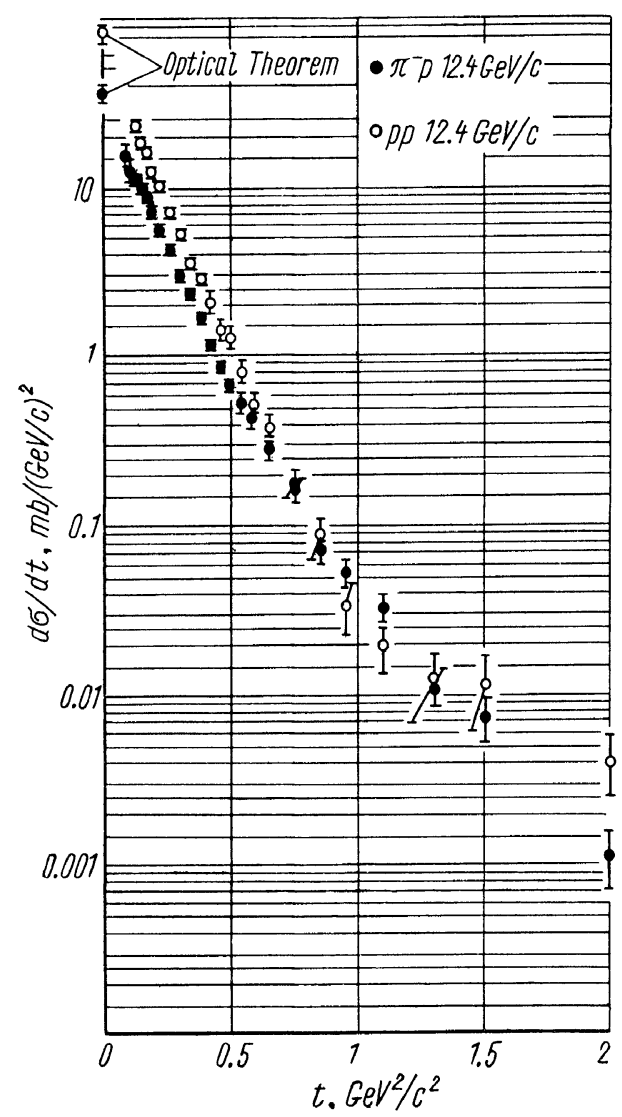

Fig. 2. $\pi^{-}-p$ and $p-p$ elastic scattering differential cross-sections at $8.5 \mathrm{GeV} / \mathrm{c}$.

measured deviations from the calculated scattered particle momentum and proton angle. The inelastic contamination is at all 6 values smaller than $2 \%$ in the councidence data and it changes from 4 to $15 \%$ in the no-proton coincidence data.

The results of this experiment are based on approximately 60 events. Fig. 2, 3, 4 and 5 show the results as $d \sigma / d t$ versus $|t|$. The $|t|$ scale is uncertain by about $1.5 \%$. It is estimated that absolute cross-sections have an uncertainty of $\pm 7 \%$.
The data have been fitted by the least mean squares method with the functions

$$
\frac{d \sigma}{d t}=\mathrm{e}^{a+b \cdot t} \mathrm{mb} /(\mathrm{GeV} / \mathrm{c})^{2}
$$

and

$$
\frac{d \sigma}{d t}=\mathrm{e}^{A+B t+C t^{2}} \mathrm{mb} /(\mathrm{Gev} / \mathrm{c})^{2} .
$$

The results of this analysis applied to our data are given in Tables 1 and 2 .

For a limited $|t|$ range, e. g. $0.1<|t|<$ $0.5(\mathrm{GeV} / \mathrm{c})^{2}$, the fit of our data to equation

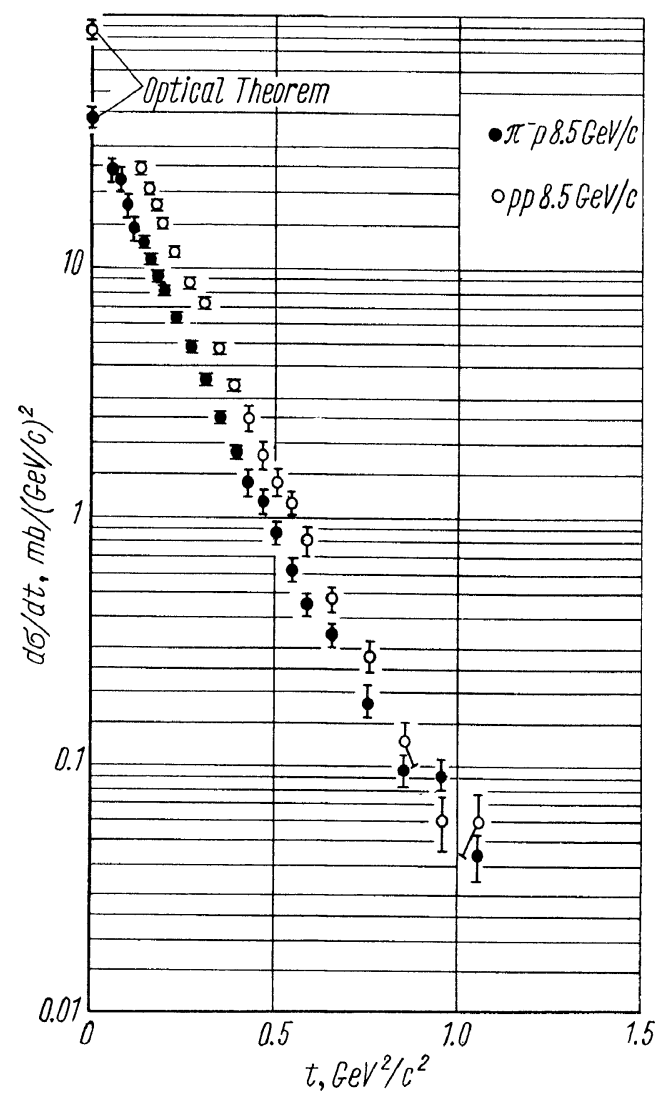

Fig. 3. $\pi^{-}-p$ and $p-p$ elastic scattering differential cross-sections at $12.4 \mathrm{GeV} / \mathrm{c}$.

(1) gives quite a reasonable $\chi^{2}$ For a larger $|t|$ range, equation (2) is required, e. g. $C$ is significantly different from zero. For the complete $|t|$ range there may be some doubts even on the validity of the formula (2).

The values for $C / B^{2}$ (typically $3 \cdot 10^{-2}$ ) show that the deviation from a pure exponential is small.

The radius of interaction, for an opaque disc may be defined as

$$
r=2 \sqrt{-b}
$$




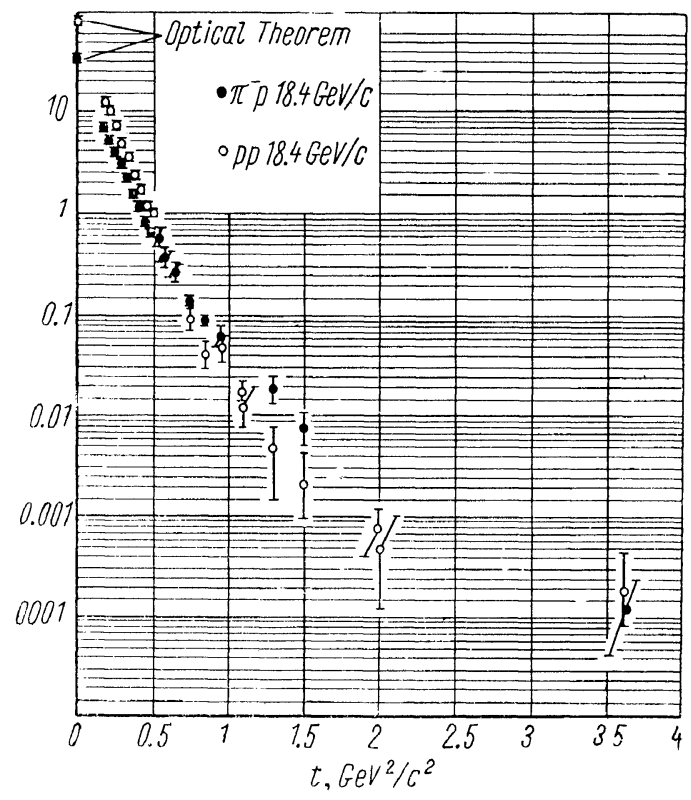

Fig. 4. $\pi^{-}-p$ and $p-p$ elastic scattering differential cross-sections at $18.4 \mathrm{GeV} / \mathrm{c}$.

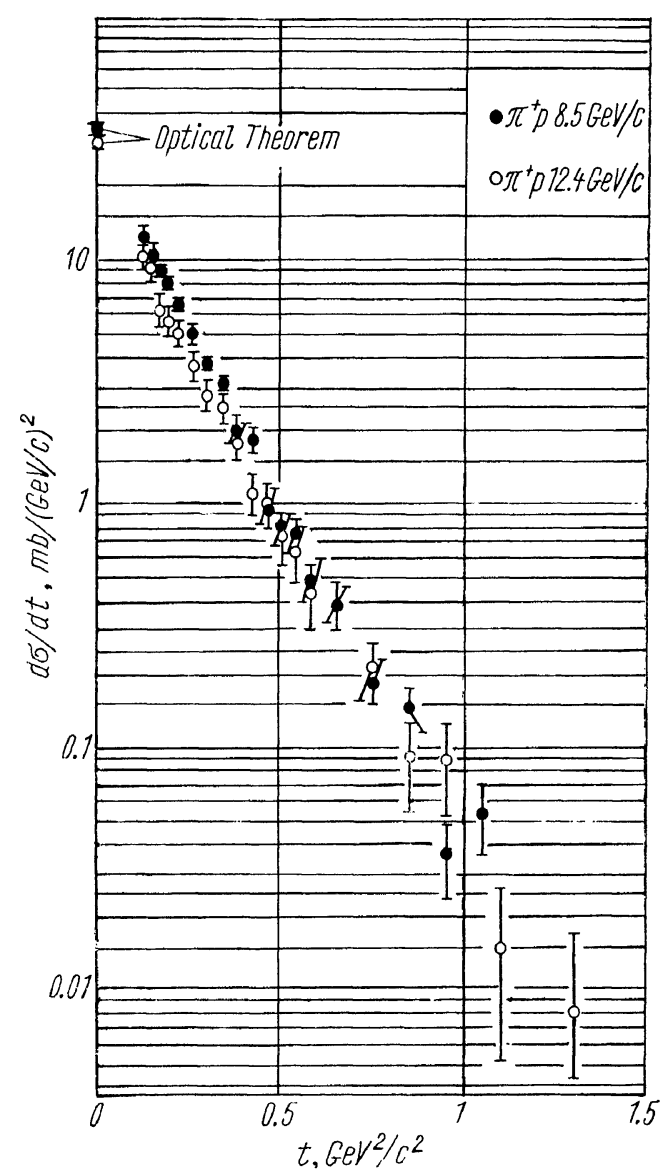

Fig. 5. $\pi^{+}-p$ elastic scattering differential cross-sections at 8.5 and $12.4 \mathrm{GeV} / \mathrm{c}$.
In Fig. 6 the results for $r$ from our experiment are shown as a function of $\log s$ and compared with those from other experiments ( $s$ is the square of the total c. m. energy). The data taken from the literature have been reanalysed so that they apply to approximately the same $|t|$ interval $(0.1<|t|<0.5)$.
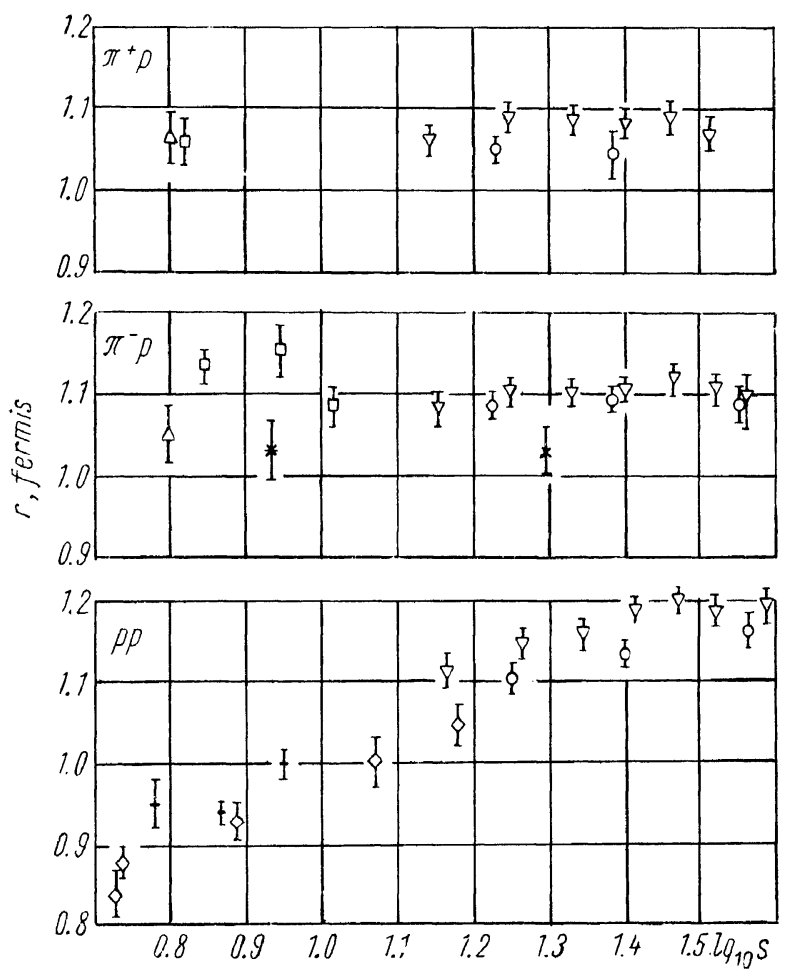

Fig. 6. Radii of interaction for $\pi^{-}-p, \pi^{+}-p$ and $p-p$ elastic scattering against $\log s$; the radius is defined as $r=2 \sqrt{-b}$ where $b$ is obtained with a purely exponential fit of the data over the region $0.13<$ $<|t|<0.5$.

While the radii for $\pi^{-}-p$ and $\pi^{+}-p$ interactions remain constant, the $p$ - $p$ interaction radius increases with $s$.

The $s$-dependence of the shape of the diffraction peak is usually expressed by the function $\alpha(t)$ in the parametrization suggested by the Regge pole theory.

From our results we find:

$$
\begin{aligned}
& p-p \alpha(t)=(1.02 \pm 0.04)-(0.65 \pm 0.12)|t| \\
& \pi^{-}-p \alpha(t)=(0.97 \pm 0.03)+(0.06 \pm 0.08)|t| \\
& \pi^{+}-p \alpha(t)=(0.71 \pm 0.19)+(0.24 \pm 0.50)|t|
\end{aligned}
$$

Thus $\alpha(t)$ has a significant $|t|$ dependence for $p \cdot p$ scattering $i$. e. the $p$ - $p$ diffraction peak shrinks. For $\pi^{-}-p$ and $\pi^{+}-p$ scattering, however, 
Least-squares adjusted values for the parameters $a$ and $b$, obtained by fitting the function $d \sigma / d t=\mathrm{e}^{a+b|t|}$ to the cross-sections measured for $|t| \leqslant 0.50$

Values of the corresponding opaque-or black-sphere target radii $r$ are given in the last column

\begin{tabular}{|c|c|c|c|c|c|c|c|c|}
\hline $\begin{array}{l}\text { Incident } \\
\text { particle }\end{array}$ & $\begin{array}{l}\text { Incident } \\
\text { momen- } \\
\text { tum, } \\
\text { GeV/c }\end{array}$ & $\begin{array}{c}s, \\
\mathrm{GeV} 2\end{array}$ & $\begin{array}{l}|t| \text { range, } \\
(\mathrm{GeV} / \mathrm{c})^{2}\end{array}$ & $\begin{array}{l}\text { No. of } \\
\text { points } \\
\text { fitted }\end{array}$ & $f^{2}$ & $a$ & $(\mathrm{GeV} / \mathrm{c})^{-2}$ & $\begin{array}{c}r, \\
\text { fermi }\end{array}$ \\
\hline$\pi^{-}$ & $\begin{array}{r}8.5 \\
12.4 \\
18.4\end{array}$ & $\begin{array}{l}16.8 \\
24.2 \\
35.4\end{array}$ & $\begin{array}{l}0.05-0.50 \\
0.09-0.50 \\
0.19-0.50\end{array}$ & $\begin{array}{r}16 \\
14 \\
9\end{array}$ & $\begin{array}{r}12.3 \\
11.5 \\
4.2\end{array}$ & $\begin{array}{l}3.521 \pm 0.022 \\
3.435 \pm 0.023 \\
3.349 \pm 0.072\end{array}$ & $\begin{array}{c}7.519 \pm 0.088 \\
7.677 \pm 0.090 \\
7.53 \pm 0.21\end{array}$ & $\begin{array}{l}1.082 \pm 0.006 \\
1.093 \pm 0.006 \\
1.083 \pm 0.015\end{array}$ \\
\hline$\pi^{+}$ & $\begin{array}{r}8.5 \\
12.4\end{array}$ & $\begin{array}{l}16.8 \\
24.2\end{array}$ & $\begin{array}{l}0.13-0.50 \\
0.13-0.50\end{array}$ & $\begin{array}{l}12 \\
12\end{array}$ & $\begin{array}{r}19.6 \\
6.4\end{array}$ & $\begin{array}{l}3.438 \pm 0.039 \\
3.185 \pm 0.094\end{array}$ & $\begin{array}{l}7.07 \pm 0.15 \\
7.10 \pm 0.35\end{array}$ & $\begin{array}{l}1.049 \pm 0.011 \\
1.045 \pm 0.026\end{array}$ \\
\hline & $\begin{array}{r}8.5 \\
12.4 \\
18.4\end{array}$ & $\begin{array}{l}17.8 \\
25.1 \\
36.3\end{array}$ & $\begin{array}{l}0.13-0.50 \\
0.13-0.50 \\
0.19-0.50\end{array}$ & $\begin{array}{r}12 \\
12 \\
9\end{array}$ & $\begin{array}{r}10.6 \\
18.7 \\
5.9\end{array}$ & $\begin{array}{l}4.198 \pm 0.028 \\
4.150 \pm 0,033 \\
4.178 \pm 0.080\end{array}$ & $\begin{array}{l}7.75 \pm 0,11 \\
8.19 \pm 0.13 \\
8.58 \pm 0.24\end{array}$ & $\begin{array}{l}1.099 \pm 0.008 \\
1.129 \pm 0.009 \\
1.156 \pm 0.016\end{array}$ \\
\hline
\end{tabular}

$\mathrm{Table} 2$

Least-squares adjusted values for the paremeters $A, B$ and $C$, obtained by fitting the function $d \sigma / d t=\mathrm{e}^{A+B|t|+C t^{2}}$ to all our measured cross-sections

\begin{tabular}{|c|c|c|c|c|c|c|c|}
\hline $\begin{array}{l}\text { Incident } \\
\text { particle }\end{array}$ & $\begin{array}{c}\text { Incident } \\
\text { momentum, } \\
\mathrm{GeV} / \mathrm{c}\end{array}$ & $\begin{array}{l}|t| \text { range } \\
(\mathrm{GeV} / \mathrm{c})^{2}\end{array}$ & $\begin{array}{l}\text { No. of, } \\
\text { points fitted }\end{array}$ & $\chi^{2}$ & $A$ & $(\mathrm{GeV} / \mathrm{c})^{-2}$ & $\begin{array}{c}\mathrm{C} \\
(\mathrm{GeV} / \mathrm{c})^{-4}\end{array}$ \\
\hline$\pi^{-}$ & $\begin{array}{r}8.5 \\
12.4 \\
18.4\end{array}$ & $\begin{array}{l}0.05-1.05 \\
0.09-2.0 \\
0.19-3.6\end{array}$ & $\begin{array}{l}23 \\
24 \\
20\end{array}$ & $\begin{array}{l}16.9 \\
30.0 \\
50.3\end{array}$ & $\begin{array}{l}3.663 \pm 0.030 \\
3.544 \pm 0.025 \\
3.326 \pm 0.050\end{array}$ & $\begin{array}{l}8.74 \pm 0.18 \\
8.65 \pm 0.12 \\
7.96 \pm 0.15\end{array}$ & $\begin{array}{l}2.17 \pm 0,22 \\
1.89 \pm 0.11 \\
1.38 \pm 0.08\end{array}$ \\
\hline$\pi^{+}$ & $\begin{array}{r}8.5 \\
12.4\end{array}$ & $\begin{array}{l}0.13-1.05 \\
0.13-1.30\end{array}$ & $\begin{array}{l}19 \\
20\end{array}$ & $\begin{array}{l}34.7 \\
10.8\end{array}$ & $\begin{array}{l}3.505 \pm 0.056 \\
3.249 \pm 0.122\end{array}$ & $\begin{array}{l}7.67 \pm 0.33 \\
7.65 \pm 0.65\end{array}$ & $\begin{array}{l}1.15 \pm 0.39 \\
1.41 \pm 0.70\end{array}$ \\
\hline$p$ & $\begin{array}{r}8.5 \\
12.4 \\
18.4\end{array}$ & $\begin{array}{l}0.13-1.05 \\
0.13-2.0 \\
0.19-3.6\end{array}$ & $\begin{array}{l}19 \\
22 \\
20\end{array}$ & $\begin{array}{l}16.7 \\
28.3 \\
17.5\end{array}$ & $\begin{array}{l}4.266 \pm 0.042 \\
4.352 \pm 0.034 \\
4.418 \pm 0.066\end{array}$ & $\begin{array}{l}8.35 \pm 0.25 \\
9.71 \pm 0.16 \\
9.96 \pm 0.21\end{array}$ & $\begin{array}{l}1.14 \pm 0.31 \\
2.33 \pm 0.14 \\
1.76 \pm 0.10\end{array}$ \\
\hline
\end{tabular}

$\alpha(t)$ is, within the errors, independent of $|t|$ and therefore the diffraction peak does not change its shape as a function of $s$.

The extrapolations of our differential crosssections to $t=0$ are not particularly significant because of the large $t$ range over which the extrapolation has to be made.

In a short run for $\pi^{-}-p$ the polarity of the last magnet (M2) was reversed, so that we accepted backward scattering angles. No elastic event was found. The configuration accepted was:

$$
13.4 \mathrm{GeV} / \mathrm{c}, \pi^{-}-p
$$$$
20.9<|t|<23.4(\mathrm{GeV} / \mathrm{c})^{2}
$$

and the upper limit on the cross-section is:

$$
\left(\frac{d \sigma}{d t}\right) /\left(\frac{d \sigma}{d t}\right)_{t=0}<6 \cdot 10^{-7}
$$

While running at $8.5 \mathrm{GeV} / \mathrm{c} \pi^{-}-p$ elastic scattering, we placed, for a short run, a $1 \mathrm{~cm}$ carbon plate between the two halves of spark chamber 9 . From the scattering of the recoiling proton through angles larger than $7^{\circ}$ one may estimate the polarization of the recoil proton, 368 unbiased events were collected. The usual checks to avoid biases were performed. While no up-down asymmetry was found, a left- 
right asymmetry seems to be present:

$\begin{array}{cc}|t| & P \\ 0.22 & 0.19 \pm 0.22 \\ 0.44 & 0.43 \pm 0.23 \\ 0.74 & 0.72 \pm 0.55 \\ \text { average } & 0.33 \pm 0.15\end{array}$

The precision of the measurement is nevertheless poor.

\section{REFERENCES}

1. Dre 11 S. D. 1962 Int. Conf. on High-Energy Physics, CERN, p. 897; S. J. L i n d e n b a u m. 1963 Int. Conf. on Nucleon Structure, Stanford, to be published; S t a $\mathrm{ng}$ h e $11 \mathrm{i} \mathrm{n}$ i A. 1963 Int. Conf. on Elementary Particles, Sienna, to be published.

2. Diddens A. N. et al. Phys. Rev. Lett., 9, 108-111 (1962)

3. Fol e y K. J. et al. Phys. Rev. Lett., 10, 376, 543 (1963) and 11, 503 (1963). 